Research Article

\title{
University Employment Quality Evaluation System Based on Multicriteria Decision and Data Analysis
}

\author{
Longhao Song (10) \\ School of Economics and Management, Beijing Jiaotong University, Beijing 100044, China \\ Correspondence should be addressed to Longhao Song; 16113117@bjtu.edu.cn
}

Received 7 October 2021; Revised 1 December 2021; Accepted 4 December 2021; Published 28 December 2021

Academic Editor: Rahman Ali

Copyright (c) 2021 Longhao Song. This is an open access article distributed under the Creative Commons Attribution License, which permits unrestricted use, distribution, and reproduction in any medium, provided the original work is properly cited.

In the educational sector, an evaluation index is required to draw up planning. The establishment of an evaluation index is useful to properly predict the employment quality of graduates. Such valuable indices help educational administrative departments to formulate talent training standards. Multicriteria decision making is a decision-making tool that can be used in the formulation of the evaluation index. This research work proposes an effective evaluation model to assess the employment quality of graduate students. The model uses 10 evaluation indicators which are considered to be the standard employment quality. The proposed evaluation method utilizes the entropy method and fuzzy comprehensive evaluation. Correlation between the employment quality evaluation index and employment quality is computed. The analytic hierarchy model is used to solve the weight of each employment quality evaluation index to the employment quality evaluation coefficient. According to the value characteristics of the 14 employment indicators, the expert method is used to assign scores to the sample data on each indicator. Thus, the indicator scores of the sample corresponding to the item are obtained. Through the evaluation of the employment quality of a certain university, the evaluation results are consistent with the actual employment quality of graduates. The employment quality evaluation model of college graduates established in this paper provides effective means and applications.

\section{Introduction}

Employment is an important issue in modern social life. Employment is the foundation of national economic development, the foundation of national stability, and the basic conditions for survival and development for individuals under market economy conditions $[1,2]$. Under the conditions of a market economy, if workers want to obtain a certain amount of labor remuneration and be able to survive and develop on their own, they must obtain it by selling labor. The concept of employment quality was initially introduced in the 1990s, and it is still an emerging research field [3]. As Sen Gupta said, it is difficult to define and measure the quality of employment [4]. In fact, there is currently no consensus on the connotation of employment quality. Crimmins et al. believes that the evaluation index of the employment quality should take more into consideration the demands of people's value realization so as to analyze the index based on Maslow's hierarchy of needs theory [5].
According to the demand theory, workers consider their own needs when they are employed; that is, the process of employment of workers is a process of satisfying their own needs, and the quality of employment is directly related to the degree of satisfaction of needs. Arranz et al. [6] believe that the opportunity for an employed individual to obtain free, equal, safe, and dignified productive work is decent work. The term work quality was proposed by the European Commission. The connotation of work quality comprehensively analyzes the characteristics of paid employment. Monfort et al. [7] put forward the concept of high-quality employment, which means that in the process of work, the subject of employment can not only get paid but also get things other than labor income, such as challenge and satisfaction. Opaas et al. [8] define the quality of employment through three dimensions, including the labor environment, the individual production efficiency of employment, and the degree of contribution to economic life through employment. 
In general, both domestic and foreign pay more attention to the research, but the research mainly focuses on the dimension of theoretical analysis $[9,10]$. The current employment quality system is not yet perfect, and the evaluation results obtained are usually one sided, ignoring the process factors that lead to the evaluation of employment quality. Current research focuses on the construction of a comprehensive evaluation system, and it is difficult to reflect the particularity of the training objectives of different types of colleges. Therefore, the construction of the index system should include general evaluation indicators that reflect the commonality of colleges and universities and the unique characteristics of different types of colleges [11, 12].

Multicriteria Decision Analysis (MCDA) is an effective tool that can be used in the decision-making process. Decision making happens to be complex, puzzler, and vagueness $[13,14]$. MCDA is a powerful tool that leads one to select the best possible option. MCDA in itself is a kind of operation research (OR) that is applicable on all sorts of data-bearing qualitative or quantitative factors [13]. MCDA intends to select the best option among a number of alternatives by taking into account various criteria. The tool helps a decision maker in focusing on what is logical, important, and easy to be followed [14]. Needless to mention, decision making is involved both in mundane and insightful activities. Therefore, MCDA has widespread applicability in various domains such as engineering, social sciences, and medicine. [15]. Moreover, in the current era of big data, multicriteria decision making is appropriate to be used in business analytics (BA) [16].

The proposed method utilizes MCDA incorporating the entropy and fuzzy comprehensive evaluation. In the research work, 10 evaluation indicators are closely related to the evaluation of employment quality. As a result, the research suggests an effective evaluation method by summing up outcomes of the study. The analytic hierarchy model is used based on the correlation between the employment quality evaluation index and employment quality. The weight of each employment quality evaluation index to the employment quality evaluation coefficient is solved for handy computation. The follow-up research work of this article helps government, universities, employers, and college students to evaluate and measure the employment quality and provide help for college graduates.

In the continuing decade of globalization, the proper evaluation of employment quality is required in terms of the ever-changing public policies and academic attendance. This proposed method provides an effective method for decision making in general and for assessing the employment quality in particular. Additionally, with little effort, the model can be enhanced to solve the decision-making issues involved in supply chain management [17].

The remaining of this paper is organized into 5 sections. The evaluation of employment quality is covered in section 2. Stepwise entropy-based evaluation is discussed in section 3. Fuzzy comprehensive evaluation is presented in section 4 . Section 5 is about conclusion and future work.

\section{Evaluation of Employment Quality in Colleges and Universities}

On the basis of real data of graduates, we inspect the association of employment quality and the representative indicators (mainly job satisfaction, satisfaction with development prospects, and social value satisfaction). We then performed regression analysis and fuzzy comprehensive evaluation based on considering the entropy weight. As a result, the correlation degree between the index factor and the employment quality is obtained. The detail of the model is given as follows:

Heidi et al. studied the impact of satisfaction on employment quality and conducted an empirical analysis. The study intends to envisage whether satisfaction can predict employment quality by investigating the research situation of employment quality and satisfaction in other countries [18]. Beatson measured the quality of employment by reflecting the economic contract, the content of the labor/ return relationship, and the psychological contract reflecting the employer/employee relationship. Fei et al. [19] used regression analysis to study the factors affecting graduates' employment competitiveness and work income. The conclusion showed that college students' academic level and their academic status were the main factors. Marin [20] believes that the strength, professional level, and influence (ranking) of colleges and universities affect the employment competitiveness of graduates. In addition, the employment policies and systems in the social environment also affect the quality of employment to a certain extent. Figure 1 shows the selection results of employment evaluation indicators for college graduates.

The research status is collected through literature research, and the expert method is applied to determine the specific indexes of the employment quality evaluation on the basis of a large number of collected documents. Next, according to the teachers and experts of the employment guidance centers of all levels of colleges and universities, opinions are analyzed and evaluated. The employment quality indicators were selected based on the standards suggested in the literature $[21,22]$. This paper follows the principles of macro-micro integration, simplicity, versatility, and comparability in selecting indicators to select 10 representative indicators that are closely related to the evaluation of employment quality. The factors include job or professional relevance, job satisfaction, job adaptation period, salary income, alma mater overall satisfaction, job salary satisfaction, job development prospect satisfaction, job consultation satisfaction, the required degree of professional demand for society, and satisfaction with employment assistance policies besides other measures [23-25].

\section{Employment Evaluation Based on Stepwise Regression Analysis}

For the multiple linear regression model $y=a v+b$, the least square estimation method can be used to estimate the parameters under the classical assumption of the model. The parameter estimator is $\widehat{a}=\left|v^{\prime} v\right|^{-1} v^{\prime} y$. The classical 


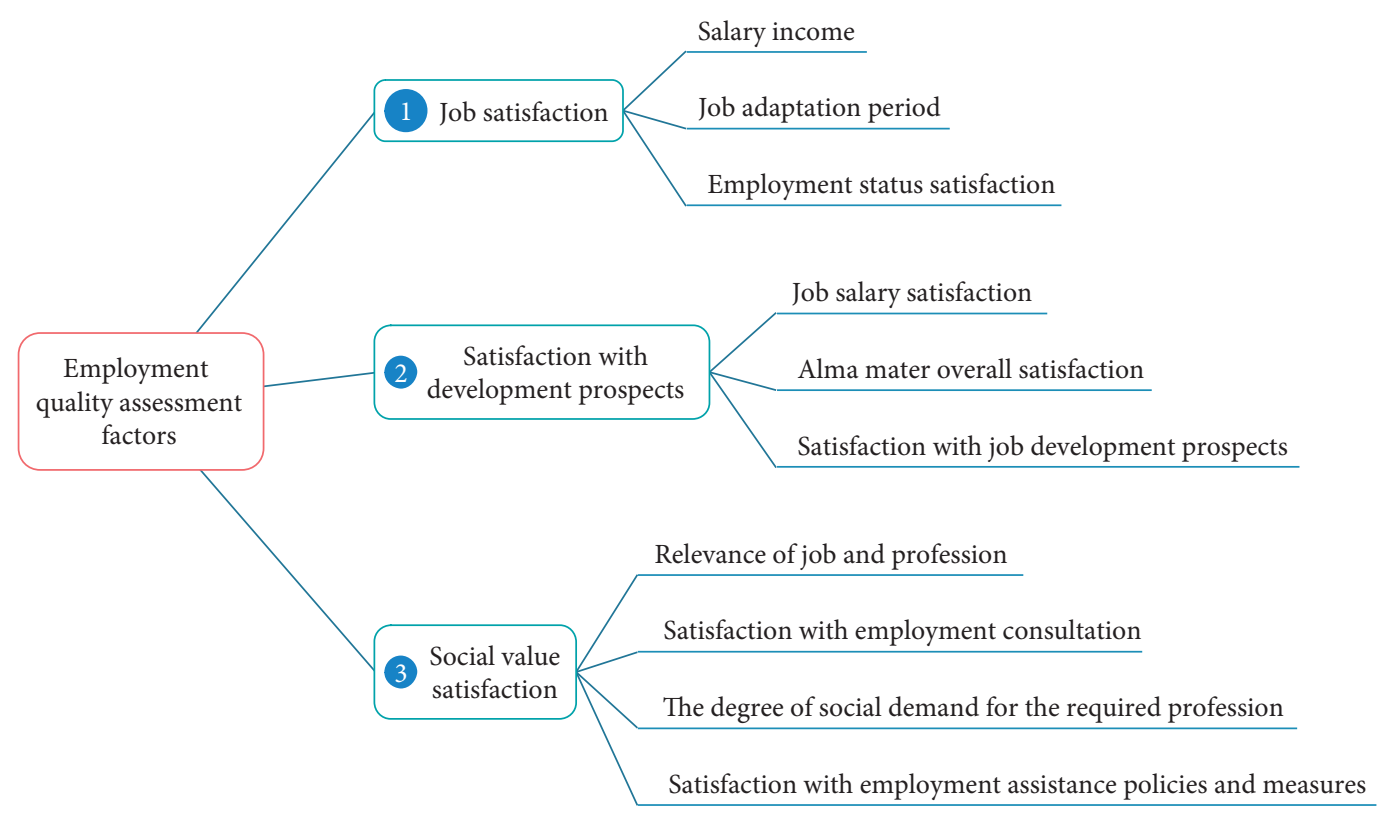

FIgURE 1: Selection of employment evaluation indicators for college graduates.

assumption is "there is no complete multicollinearity." However, in the analysis of real economic problems, it is impossible to have completely linear independence among explanatory variables. If there is a linear correlation between the explanatory variables $v_{1}, v_{2}, v_{3} \ldots v_{i}$, there must be $\left|v^{\prime} v\right|=0$, so $\left|v^{\prime} v\right|^{-1}$ does not exist, and the least square estimator of the parameter is not unique. This means that the least square estimation method is invalid, and the model has multicollinearity $[26,27]$. Stepwise regression analysis not only can test the multicollinearity but also is an effective method to deal with the multicollinearity problem. The following step-by-step approach is followed for analysis.

STEP 1. According to the law of economics and relevant subjective experience analysis, select the relevant independent variables and set that as $v_{1}, v_{2}, v_{3} \ldots v_{i}$.

STEP 2. Use each independent variable to establish a regression model for the explained variable $y$ to get the regression models.

$$
\left\{\begin{array}{l}
y=a_{11}+a_{12} v_{1}+b_{1}, \\
y=a_{21}+a_{22} v_{21}+b_{2}, \\
\cdots \ldots . . \\
y=a_{i 1}+a_{i 2} v_{i}+b_{i} .
\end{array}\right.
$$

STEP 3. STEP1. carries out parameter estimation and testing. The model with the smallest sum of squared residuals among the tested models is selected as the preferred model, or the regression equation with the largest goodness of fit is selected as the preferred model.

STEP 4. Add other explanatory variables one by one in the preferred model and perform linear regression again. The newly added explanation improves the goodness of fit of the regression equation [28-30]. It is possible that some parameters in the regression equation may be higher. However, the value of some parameters in the regression equation is significantly affected. In the model $[31,32]$, steps are proposed for the influence and existence of multicollinearity. The steps are as follows:

The least square estimation is carried out on the above i-1 models, respectively. The t-test statistics of the goodness of fit and the parameters of each model are obtained. Bring A into STEP2, and the model is built and obtained as follows:

$$
\left\{\begin{array}{l}
y=a_{11}+a_{12} v_{1}+a_{13} v_{2}+b_{1}, \\
y=a_{22}+a_{22} v_{2}+a_{23} v_{2}+b_{2}, \\
\cdots \ldots . . \\
y=a_{i 1}+a_{i 2} v_{i}+a_{i 3} v_{i}+b_{i} .
\end{array}\right.
$$

In the analysis of multicollinearity, if the coefficient value or even the sign in the model with the new variable changes significantly so that the result is unacceptable, it is very likely that there is multicollinearity. Thus, the new variable cannot be introduced into the model $[33,34]$. Figure 2 shows the standard P-P plot of the regression standardized residuals.

In a model with multicollinearity or a model with insignificant multicollinearity, the model is selected with the most significant improvement, and the next step is proceeded. Then, statistic A is established as follows:

$$
F=\frac{(n-j-1) Q(j-1)-Q(j)}{Q(j)} .
$$

$Q(j)$ is the residual sum of squares when the model includes $j$ variables, and the significance level is given.

If $F_{j}>F_{a}$, then a new variable is added, and the new variable cannot be added, otherwise. The steps are repeated until a satisfactory model is established. In the analysis of 


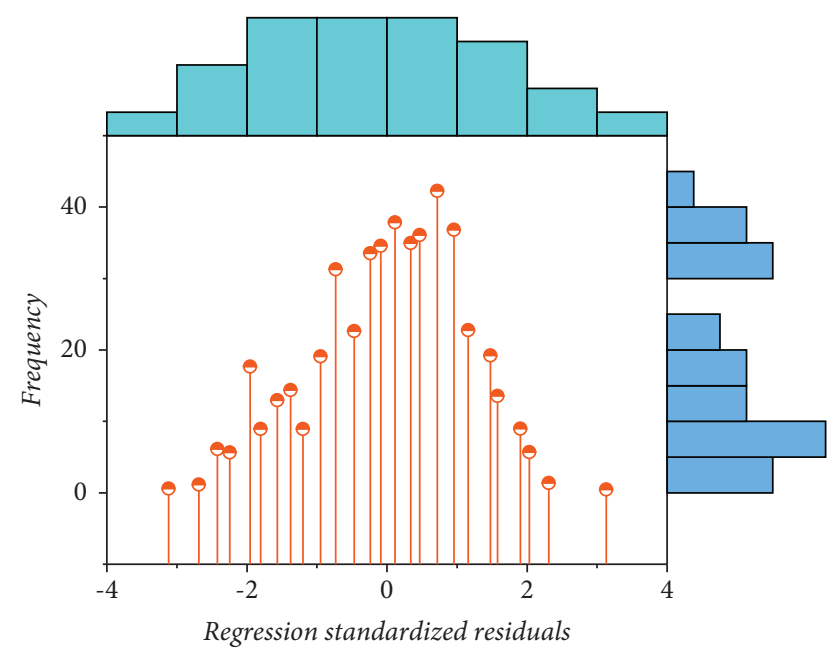

FIGURE 2: Standard P-P plot of regression standardized residuals.

multicollinearity, if the coefficient value or even the sign in the model with the new variable changes significantly so that the result is unacceptable, it is very likely that there is multicollinearity. Therefore, no new variable can be introduced into the model.

\section{Fuzzy Comprehensive Evaluation and Comparison Scheme Model Based on Entropy Weight Method}

Employment is a very important issue in modern social life. Employment is the foundation of the national economy and national stability. It is considered to be the basic conditions for the survival and development of individuals under market economy conditions. At present, the methods for evaluating the employment quality of college graduates are relatively simple. There is no overall planning and reevaluation based on of standard relevant principles. There is a lack of scientific demonstration in statistical analysis methods and investigation time nodes $[35,36]$. This study uses a combination of qualitative analysis and quantitative analysis to systematically analyze the relevant factors affecting the employment quality of college graduates. From the connotation of employment quality, an index system is designed so that to ensure expert evaluation. The method relies on the empirical conclusions of a large sample of college graduates. The research is significant in the sense that both qualitative and quantitative research methods are being used. The study is more comprehensive, in-depth, and scientific. Furthermore, the method is suitable to understand the nature of college graduates' employment quality. Outcomes of the research are based on real data gathered from university and college students [37].

In a nutshell, the paper compares and contrasts the schemes through the fuzzy comprehensive evaluation and comparison scheme model based on the entropy weight method. The proposed model plainly and systematically solves the vague and difficult-to-quantify problem of the degree of impact.
4.1. Determination of Price Index System. The proposed research follows the principles of macro-micro integration, simplicity, versatility, and comparability in selecting the indicators. There are 10 representative indicators that are closely related to the evaluation of employment quality. The key indicators include job and professional relevance, satisfaction with employment status, job adaptation period, salary income, alma mater, overall satisfaction, job salary satisfaction, job development prospect satisfaction, employment consultation, and degree of social demand, satisfaction with employment assistance policies, and other measures.

4.2. Establishing an Evaluation Set of the Completion of Task Points. The principles of macro-micro integration, simplicity, versatility, and comparability are followed in the selecting indicators. As mentioned in the previous section, a total of 10 representative indicators were used. The indicators are closely related to the evaluation of employment quality. In order to better illustrate the degree of completion of the task point, the evaluation factors in the degree of influence are divided into five levels, namely, the evaluation set. The five levels respectively indicate that the task completion is very good $(4-5)$, good $(3 \sim 4)$, general $(2 \sim 3)$, poor $(1 \sim 2)$, and very poor $(0 \sim 1)$ are expressed by A $\sim$ E. Table 1 shows the classification of the evaluation set of the employment quality evaluation.

\subsection{Establishing Membership Function for Factor Evaluation.} In order to reduce the influence of subjective factors when assigning membership values by methods such as expert scoring, the ascending and descending half trapezoidal distribution functions are adopted as the membership functions for factor evaluation. Taking the task completion time as an example, first, a five-level membership function is made according to the five-level standard of the waiting time indicator. Among the evaluation factor, a smaller value of the evaluation index of the completion time is considered to be best. Initially, as the first plan, the reduced-half trapezoidal distribution membership function of the completion is established. Following that, the ascending half trapezoidal distribution membership functions of unit distance revenue, regional average pricing, and task completion rate are established, respectively. In the same way, the membership functions of the ascending and descending semitrapezoidal distributions of the evaluation factors of the second scheme are established.

Through the evaluation factor membership function, the membership subset of the task completion time is obtained. This is carried out in accordance with the data in the appendix, that is, the fuzzy evaluation matrix.

4.4. Establishing a Weight Set of Evaluation Factors. The identified factors such as unit distance revenue, regional average pricing, task completion rate, and task completion time have different effects on task completion. Therefore, different weights should be assigned to each indicator. The 
TABle 1: The classification of the quality evaluation.

\begin{tabular}{|c|c|c|c|c|c|c|}
\hline Serial number & Evaluation factor & $A(1)$ & $B(2)$ & $C(3)$ & $D(4)$ & $E(5)$ \\
\hline 1 & Unit evaluation benefit $x_{1}$ & $x_{1}<0.5$ & $0.5 \leq x_{1}<1.0$ & $1.0 \leq x_{1}<1.5$ & $1.5 \leq x_{1}<2.0$ & $x_{1} \geq 2.0$ \\
\hline 2 & Regional assessment quality $x_{2}$ & $65 \leq x_{2}<7$ & $70 \leq x_{2}<75$ & $75 \leq x_{2}<80$ & $80 \leq x_{2}<85$ & $x_{2} \geq 85$ \\
\hline 3 & Assessment completion rate $x_{3}(\%)$ & $x_{3}<5$ & $65 \leq x_{3}<70$ & $70 \leq x_{3}<75$ & $75 \leq x_{3}<80$ & $x_{3} \geq 80$ \\
\hline 4 & Time to complete the assessment $x_{4}$ & $x_{4}<5$ & $5 \leq x_{4} 10$ & $10 \leq x_{4}<15$ & $15 \leq x_{4}<20$ & $\geq 20$ \\
\hline
\end{tabular}

weight is determined according to the principle that each factor has a great influence on the completion of the task and the principle of great weight. Figure 3 depicts results of the relevance of employment quality indicators in colleges and universities.

The highest correlation degree between each index and the reference sequence of employment quality reached 0.778 , the lowest correlation degree was 0.428 , and the correlation degree of other indicators remained between 0.5 and 0.8 .

The correlation results of the indicators are shown in Table 2, where the A index reflects the calculated proportion of the index value of the item.

$$
\begin{aligned}
& p_{\mathrm{ij}}=\frac{r_{i j}}{\sum_{i=2}^{m} r_{\mathrm{ij}}}, \\
& e_{j}=-k \sum_{i=1}^{m} p_{\mathrm{ij}} \cdot \operatorname{In} p_{\mathrm{ij}} .
\end{aligned}
$$
follows:

The entropy weight $w_{j}$ of the $j$-th index is computed as

$$
w_{j}=\frac{1-e_{j}}{\sum_{j=1}^{n} 1-e_{j}} .
$$

The comprehensive weight of the indicator $\beta_{j}$ is given as follows:

$$
\beta_{j}=\frac{\alpha_{j} \omega_{j}}{\sum_{j=1}^{m} \alpha_{i} \omega_{i}} .
$$

The calculated weights are $0.127,0.233,0.362$, and 0.278 , respectively. Mathematically, the weight set of each evaluation factor is represented as follows:

$$
\omega_{1}=[0.127,0.233,0.362,0.278] .
$$

4.5. Fuzzy Comprehensive Evaluation. the weight of the evaluation factor and the evaluation result $S$ is combined, where $S=\omega \times R$. The obtained first-level fuzzy evaluation matrix of the scheme one and the scheme two is given as follows:

$$
\begin{aligned}
S & =\left[\begin{array}{lllll}
0.341 & 0.260 & 0.243 & 0.222 & 0.324
\end{array}\right] \\
S^{\prime} & =\left[\begin{array}{lllll}
0.277 & 0.386 & 0.325 & 0.302 & 0.252
\end{array}\right] .
\end{aligned}
$$

According to $\omega$, the compound operation and normalization of the fuzzy matrix are computed to obtain the fuzzy comprehensive evaluation vector of the completion of the task point as

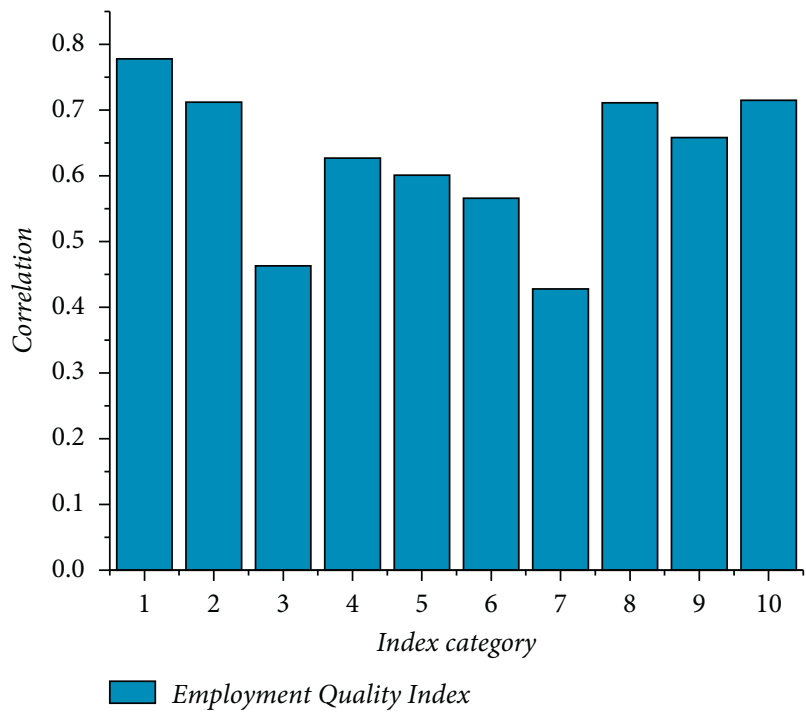

FIGURE 3: Relevant results of employment quality indicators in colleges and universities.

$$
\begin{aligned}
& Y=\omega \cdot S \\
& =\left[\begin{array}{lllll}
0.212 & 0.168 & 0.232 & 0.106 & 0.095
\end{array}\right], \\
& Y=\omega \cdot S^{\prime} \\
& =\left[\begin{array}{lllll}
0.29 & 0.25 & 0.38 & 0.27 & 0.12
\end{array}\right] \text {. }
\end{aligned}
$$

The fuzzy comprehensive evaluation vector is scored, and the scores of the two schemes are obtained as follows:

$$
\begin{aligned}
\text { Score }_{1} & =0.212 \times 1+0.168 \times 2+0.232 \times 3+0.106 \times 4+0.095 \times 5 \\
& =2.143, \\
\text { Score }_{2} & =0.291+0.25 \times 2+0.38 \times 3+0.27 \times 4+0.12 \times 5 \\
& =361 .
\end{aligned}
$$

The score of option one is 2.143 points, indicating that the task completion of option one is average or poor, while the score of option two is 3.61 points. This indicates that the task of option two has been largely completed which in turn shows that the completion situation is better. In the analysis of multicollinearity, if the coefficient value or the sign in the model with the new variable changes significantly, then the result would be unacceptable. Moreover, the probability of multicollinearity would be high. This signifies that a new variable cannot be introduced into the model. It is therefore deduced that the second option is more suitable to be used as a strategy than the first option. It is because the related task is 
TABLE 2: Relevant results of indicators.

\begin{tabular}{lccccc}
\hline Index & $\mathrm{A} 1$ & $\mathrm{~A} 2$ & $\mathrm{~A} 3$ & $\mathrm{~A} 4$ & $\mathrm{~A} 5$ \\
\hline Correlation & 0.778 & 0.712 & 0.463 & 0.627 & 0.601 \\
Index & $\mathrm{A} 6$ & $\mathrm{~A} 7$ & $\mathrm{~A} 8$ & $\mathrm{~A} 9$ & $\mathrm{~A} 10$ \\
Correlation & 0.566 & 0.428 & 0.711 & 0.658 & 0.715 \\
\hline
\end{tabular}

comparatively more completed. According to the results of the fuzzy evaluation of the employment quality level of college students, this article again uses a quantitative method. Analogously, the index weights are used as the weighted average to calculate the score value of the first employment quality level of the college students. The fuzzy comprehensive evaluation results are then obtained accordingly. The verification process is based on the data collected via a questionnaire. All the factors are represented by variables in the questionnaire. The mean value of the total variable is calculated by the statistical software to accurately verify the mentioned evaluation results.

\section{Conclusion and Future Work}

Under the conditions of a market economy, if workers want to obtain a certain amount of labor remuneration, it is ought to be paid. To be able to survive and develop on their own, workers must obtain their due wage by selling their labor. The concept of employment quality originally appeared in the 1990s, and it is still an emerging research area. Feedback on the construction of the employment quality evaluation system for college graduates is advantageous in many ways. It helps the concerned to comprehensively and objectively grasp the employability level of college graduates. Moreover, it is useful to investigate the actual economic and social development requirements of the graduates, all according to their talents. The literature on the employment quality evaluation of college graduates is thoroughly studied and a number of analyses are carried out in the paper. A systematic questionnaire survey was carried out to collect data related to employment aptitude. The combinational approach followed encompassing the entropy weight method to mine the employment sample data. Firstly, data are quantified and then normalized for efficient utilization. Following that, the correlation analysis model is performed on the index sequence to obtain the correlation degree between the index factor and the employment quality. The impact of each indicator is then determined on the "employment quality." Next, the analytic hierarchy model is used to obtain the weight of each indicator factor. The expert method is used to score the original index factors of the original data, thereby dividing the grade. Employment quality evaluation is a diversified and complex system. Some difficult problems and unavoidable factors have been encountered in the research process. In short, shortcomings are still there, which need to be improved by investigating further research in the domain. The model is ready to be enhanced for the decision-making process in other fields. We are determined to present various versions of the model to simplify decision making in project management and risk management.

\section{Data Availability}

The data used to support the results of this study are included in this article.

\section{Conflicts of Interest}

The authors declare that they have no conflicts of interest.

\section{References}

[1] X. Jiang, "Employment effects of trade in intermediate and final goods: an empirical assessment," International Labour Review, vol. 154, no. 2, pp. 147-164, 2015.

[2] L. C. Degrossi, J. P. Albuquerque, R. D. S. Rocha, and A. Zipf, "A taxonomy of quality assessment methods for volunteered and crowdsourced geographic information," Transactions in GIS, vol. 22, no. 2, pp. 542-560, 2018.

[3] M. C. Campion, E. D. Campion, and M. A. Campion, "Using practice employment tests to improve recruitment and personnel selection outcomes for organizations and job seekers," Journal of Applied Psychology, vol. 104, no. 9, pp. 1089-1102, 2019.

[4] M. Kobayashi and E. Usui, "Breastfeeding practices and parental employment in Japan," Review of Economics of the Household, vol. 15, no. 2, pp. 579-596, 2017.

[5] G. Crimmins, G. Nash, F. Oprescu et al., "Can a systematic assessment moderation process assure the quality and integrity of assessment practice while supporting the professional development of casual academics?" Assessment \& Evaluation in Higher Education, vol. 41, 2015.

[6] J. M. Arranz, C. G Serrano, and V. Hernanz, "Employment quality: are there differences by types of contract?" Social Indicators Research, vol. 137, no. 1, pp. 203-230, 2018.

[7] S. S. Monfort, G. W. Howe, C. D. Nettles, and K. L. Weihs, “A longitudinal examination of re-employment quality on internalizing symptoms and job-search intentions," Journal of Occupational Health Psychology, vol. 20, no. 1, pp. 50-61, 2015.

[8] M. Opaas, E. Hartmann, T. W. Larsen, and S. Varvin, "Relationship of pretreatment rorschach factors to symptoms, quality of life, and real-life functioning in a hin3-year followup of traumatized refugee patients," Journal of Personality Assessment, vol. 98, 2015.

[9] R. Bottiroli, M. Pedrotti, E. Aprea, F. Biasioli, V. Fogliano, and F. Gasperi, "Application of ptr-tof-ms for the quality assessment of lactose-free milk: effect of storage time and employment of different lactase preparations," Journal of Mass Spectrometry, vol. 55, Article ID e4505, 2020.

[10] A. R. D. Rosa, F. Leone, F. Cheli, and V. Chiofalo, "Fusion of electronic nose, electronic tongue and computer vision for animal source food authentication and quality assessment - a review," Journal of Food Engineering, vol. 210, pp. 62-75, 2017.

[11] J. Campbell, W. Rashid, M. Cercignani, and D. Langdon, "Cognitive impairment among patients with multiple sclerosis: associations with employment and quality of life," Postgraduate Medical Journal, vol. 93, no. 1097, pp. 143-147, 2017.

[12] R. Robinson, E. Okpo, and N. Mngoma, "Interventions for improving employment outcomes for workers with hiv," Cochrane Database of Systematic Reviews, vol. 5, no. 5, Article ID CD010090, 2015.

[13] A. Mardani, A. Jusoh, K. M. Nor, Z. Khalifah, N. Zakwan, and A. Valipour, "Multiple criteria decision-making techniques 
and their applications - a review of the literature from 2000 to 2014," Economic Research-Ekonomska Istraživanja, vol. 28, no. 1, pp. 516-571, 2015.

[14] B. Sarkar, "Fuzzy decision making and its applications in cotton fibre grading," Soft Computing in Textile Engineering, vol. 12, no. 3, pp. 353-383, 2011.

[15] I. Ozsahin, D. U. Ozsahin, and B. Uzun, Eds., Applications of Multi-Criteria Decision-Making Theories in Healthcare and Biomedical Engineering, Academic Press, Cambridge, MA, USA, 2021.

[16] R. Ramanathan, M. Mathirajan, and A. R. Ravindran, Eds., Big Data Analytics Using Multiple Criteria Decision-Making Models, CRC Press, Boca Raton, FL, USA, 2017.

[17] S. A. Khan, A. Chaabane, and F. T. Dweiri, "Multi-criteria decision-making methods application in supply chain management: A systematic literature," Multi-criteria methods and techniques applied to supply chain management, vol. 1, 2018.

[18] J. Heidi, B. Lutgart, D. C. Bart, D. B. Dirk, and C. Els, "The relation between indicators of low employment quality and attendance behavior in countries of the European Union," Journal of Public Health, vol. 39, no. 4, p. 4, 2017.

[19] L. Fei, Y. Deng, and Y. Hu, "Ds-vikor: a new multi-criteria decision-making method for supplier selection," International Journal of Fuzzy Systems, vol. 21, 2019.

[20] S. Beeram, M. Srinivas, S. P. Raj, and K. S. Reddy, "Selection of sustainable juice extraction techniques for non-centrifugal sugar industry using multi-criteria decision-making methods," Journal of Food Process Engineering, vol. 43, no. 7, 2020.

[21] S. M. Kotikot, B. Kar, and O. A. Omitaomu, "A geospatial framework using multicriteria decision analysis for strategic placement of reserve generators in puerto rico," IEEE Transactions on Engineering Management, vol. 67, no. 99, pp. 1-11, 2020.

[22] A. Garre, G. Boué, P. S. Fernández, J. M. Membré, and J. A. Egea, "Evaluation of multicriteria decision analysis algorithms in food safety: a case study on emerging zoonoses prioritization," Risk Analysis: An Official Publication of the Society for Risk Analysis, vol. 40, pp. 336-351, 2020.

[23] H. Vallecha, D. Bhattacharjee, J. K. Osiri, and P. Bhola, "Evaluation of barriers and enablers through integrative multicriteria decision mapping: developing sustainable community energy in indian context," Renewable and Sustainable Energy Reviews, vol. 138, Article ID 110565, 2020.

[24] E. Unay, B. Ozkaya, and H. C. Yoruklu, "A multicriteria decision analysis for the evaluation of microalgal growth and harvesting," Chemosphere, vol. 279, 2021.

[25] C. Jana, G. Muhiuddin, and M. Pal, "Multi-criteria decision making approach based on svtrn dombi aggregation functions," Artificial Intelligence Review, vol. 6, no. 11, 2020.

[26] H. Vallecha, D. Bhattacharjee, J. K. Osiri, and P. Bhola, "Evaluation of barriers and enablers through integrative multicriteria decision mapping: developing sustainable community energy in indian context," Renewable and Sustainable Energy Reviews, vol. 138, 2021.

[27] M. Mokarram, M. J. Mokarram, M. R. Khosravi, A. Saber, and A. Rahideh, "Determination of the optimal location for constructing solar photovoltaic farms based on multi-criteria decision system and dempster-shafer theory," Scientific Reports, vol. 10, no. 1, 2020.

[28] T. D. Wagdy, E. H. Ibrahim, and G. Wajeb, "A trust framework utilization in cloud computing environment based on multi-criteria decision-making methods," The Computer Journal, vol. 8, no. 7, 2021.
[29] M. Couceiro, M. Maróti, T. Waldhauser, and L. Zádori, "Computing version spaces in the qualitative approach to multicriteria decision aid," International Journal of Foundations of Computer Science, vol. 30, no. 2, pp. 333-353, 2019.

[30] C. N. Wang and A. P. Le, "Application of multi-criteria decision-making model and gm $(1,1)$ theory for evaluating efficiency of fdi on economic growth: a case study in developing countries," Sustainability, vol. 11, no. 8, 2019.

[31] Y. Wu and T. Zhang, "Risk assessment of offshore wave-windsolar-compressed air energy storage power plant through fuzzy comprehensive evaluation model," Energy, vol. 223, no. 5, Article ID 120057, 2021.

[32] B. Hou, Z. Huang, H. Zhou, and D. Li, "A hybrid hint-based and fuzzy comprehensive evaluation method for optimal parting curve generation in injection mold design," International Journal of Advanced Manufacturing Technology, vol. 112 , no. 12,2021

[33] J. Wei, G. Li, D. Xie, G. Yu, and J. Wang, "Discrimination of mine water-inflow sources based on the multivariate mixed model and fuzzy comprehensive evaluation," Arabian Journal of Geosciences, vol. 13, no. 17, 2020.

[34] Z. Chen, M. Shi, and J. Zou, "Application of improved fuzzy comprehensive evaluation method in eutrophication assessment for tributary bays in the three gorges reservoir, china," Water Environment Research, vol. 93, 2020.

[35] D. Liang, Z. Dai, and M. Wang, "Assessing customer satisfaction of o2o takeaway based on online reviews by integrating fuzzy comprehensive evaluation with ahp and probabilistic linguistic term sets," Applied Soft Computing, vol. 98, no. 4, Article ID 106847, 2020.

[36] B. Sun and X. Zhang, "Research on the safety assessment of rc workshop buildings in earthquake site based on the fuzzy comprehensive evaluation," Structural Concrete, vol. 21, no. 3, 2020.

[37] Y. Lu, J. Zheng, C. Zhao, G. Ren, and M. Engineering, "Risk assessment of a cryogenic globe valve by using combined group decision and fuzzy comprehensive evaluation," Mathematical Problems in Engineering, vol. 2021, Article ID 6666126, 8 pages, 2021. 